\title{
Cell for Simultaneous Synchrotron Radiation X-ray and Electrochemical Corrosion Measurements on Cultural Heritage Metals and Other Materials
}

\author{
Mark G. Dowsett*,† and Annemie Adriaens* \\ Department of Physics, Warwick University, Coventry, CV4 7AL, UK, and Department of Analytical Chemistry, \\ Ghent University, Krijgslaan 281-S12, B-9000 Ghent, Belgium
}

We describe the construction of an electrochemical cell of the Bragg type suitable for in situ synchrotron X-ray measurements on rough, heterogeneous metals such as cultural heritage alloys and simulants with corroding or passivated surfaces. The cell features a working electrode, which may be moved under remote control from a position close to an X-ray window to full immersion in the electrolyte. A pocket of electrolyte in contact with the bulk can be maintained on the working electrode surface at all times. Its thickness (typically 100-200 $\mu \mathrm{m}$ ) can be controlled by adjusting the working electrode position and, independently, altering the conformation of the X-ray window with hydrostatic pressure. Alternatively, the electrode may be lowered into the bulk of the electrolyte. Early results from the cell showing a time-resolved study of the reduction of nantokite to cuprite in sodium sesquicarbonate, accompanied by corrosion potential measurements obtained in parallel, are presented here.

The application of electrochemical techniques for the stabilization, cleaning, and protection of metallic cultural heritage objects from silverware to battleships ${ }^{1-6}$ is proving to be extremely effective, and research in this area has increased significantly in the past 10 years. The value and uniqueness of some of the objects involved, together with other issues such as their location, means that all conservation treatments must be thoroughly understood and tested, preferably before first use. The consequences of failure range from the loss of an irreplaceable museum object to serious environmental damage (e.g., in the case of fuel leakage from a sunken World War 2 battleship). ${ }^{7}$ In addition, there is a need for fully qualified but simple in situ monitoring techniques that can be used by conservators, for example, corrosion potential $\left(E_{\text {corr }}\right)$

\footnotetext{
* To whom correspondence should be addressed. E-mail: m.g.dowsett@ warwick.ac.uk.

$\dagger$ Warwick University.

* Ghent University.

(1) Costa, V. In Conservation Science 2002; Townsend, J. T.; Eremin, K.; Adriaens, A., Eds.; Archetype: London, 2003; pp 88-95.

(2) Degrigny, C. Cahier Technique de l'Araafu 2001, 7, 32-35.

(3) Degrigny, C.; Lacoudre, N. In A la Recherche du Métal Perdu; Roudet-Meyer, H., Ed.; Errance: Paris, 1999; pp 114-127.

(4) Eggert, G. In Metallrestaurierung; Heinrich, P., Ed.; Callwey: München, 1994; pp 126-137.

(5) Espié, L.; Lacoudre, N.; Beldjoudi, T.; Dugot, J. Techné 2000, 12, 19-27.

(6) North, N. A. In Conservation of Marine Archaeological Objects; Pearson, C., Ed.; Butterworth-Heinemann: London, 1987; pp 207-252.
}

measurements on artifacts stored in stabilizing media (such as marine objects immersed in sodium sesquicarbonate solution). ${ }^{8,9}$

There exist many techniques that can be used for the ex situ study of real and simulated surfaces (e.g., analytical electron microscopy, various electron spectroscopies, mass spectrometric techniques ${ }^{10-13}$ ). In most cases, these require that the sample is placed in an untypical environment such as a vacuum and the relationship between such measurements and the surface chemistry in the native state is rarely established. Moreover, it is only recently that it has become possible, using these techniques, to observe reactions at the liquid-metal interface as they occur. ${ }^{10}$

In 1980, Fleischmann et al. described the first in situ observation of electrochemical reactions at the liquid-solid interface using X-ray diffraction (XRD) $\cdot{ }^{15} \mathrm{~A}$ few years later, Fleischmann et al. published some of the earliest designs for electrochemical cells for use with a variety of synchrotron X-ray (SR-X...) techniques. ${ }^{16}$ Since then, the use of SR-XRD, synchrotron X-ray absorption spectroscopy (SR-XAS), and electrochemistry has been described by a number of authors, ${ }^{17-25}$ many of whom have published

(7) MacLeod, I.; Morrison, P.; Richards, V.; West, N. In Metal 04; Ashton J., Hallam, D., Eds.; National Museum of Australia: Canberra, 2004; pp 5374.

(8) Degrigny, C.; Spiteri, L. In Metal 04; Ashton J., Hallam, D., Eds.; National Museum of Australia: Canberra, 2004; pp 315-331.

(9) Leyssens, K.; Adriaens, A.; Pantos, E.; Degrigny C. In Metal 04; Ashton J., Hallam, D., Eds.; National Museum of Australia: Canberra, 2004; pp 332343.

(10) Guay, D.; Stewart-Ornstein, J.; Zhang, X.; Hitchcock, A. P. Anal. Chem. 2005, 77, 3479-3487.

(11) Lacoudre, N., Beldjoudi, T., and Dugot, J., In Metal 98, Mourey, W., Robbiola, L. Eds.; James and James, 1998; pp 265-270.

(12) Dowsett, M. G.; Adriaens, A.; Soares, M.; Wouters, H.; Palitsin, V. V. N.; Gibbons, R.; Morris, R. J. H. Nucl. Instrum. Methods Phys. Res. B 2005, 239, 51-64.

(13) Janssens, K., Van Grieken, R., Eds. Non-Destructive Microanalysis of Cultural Heritage Materials; Elsevier: Amsterdam, 2004.

(14) Nord, A. G.; Tronner, K. Stud. Conserv. 2000, 45, 274-279.

(15) Fleischmann, M.; Hendra, P. J.; Robinson, J. Nature 1980, 288, 152-154.

(16) Fleischmann, M.; Oliver, A.; Robinson, J. Electrochim. Acta 1986, 31, 899906.

(17) Long, G. G.; Kruger, J.; Black, D. R.; Kuriyama, M. J. Electrochem. Soc. 1983, $130,240-242$.

(18) Kerkar, M.; Robinson, J.; Forty, A. J. Faraday Discuss. Chem. Soc. 1990 , $89,31-40$.

(19) Schmuki, P.; Virtanen, S.; Isaacs, H. S.; Ryan, M. P.; Davenport, A. J.; Böhni, H.; Stenberg, T. J. Electrochem. Soc. 1998, 145, 791-801.

(20) Nagy, Z.; You, H. Electrochim. Acta 2002, 47, 3037-3055.

(21) Lucas, C. A. Electrochim. Acta 2002, 47, 3065-3074.

(22) Hecht, D.; Borthen, P.; Strehblow, H. H. J. Electrochem. Soc. 1995, 381, 113-121.

10.1021/ac052125y CCC: $\$ 33.50$ @ 2006 American Chemical Society Published on Web 04/14/2006 


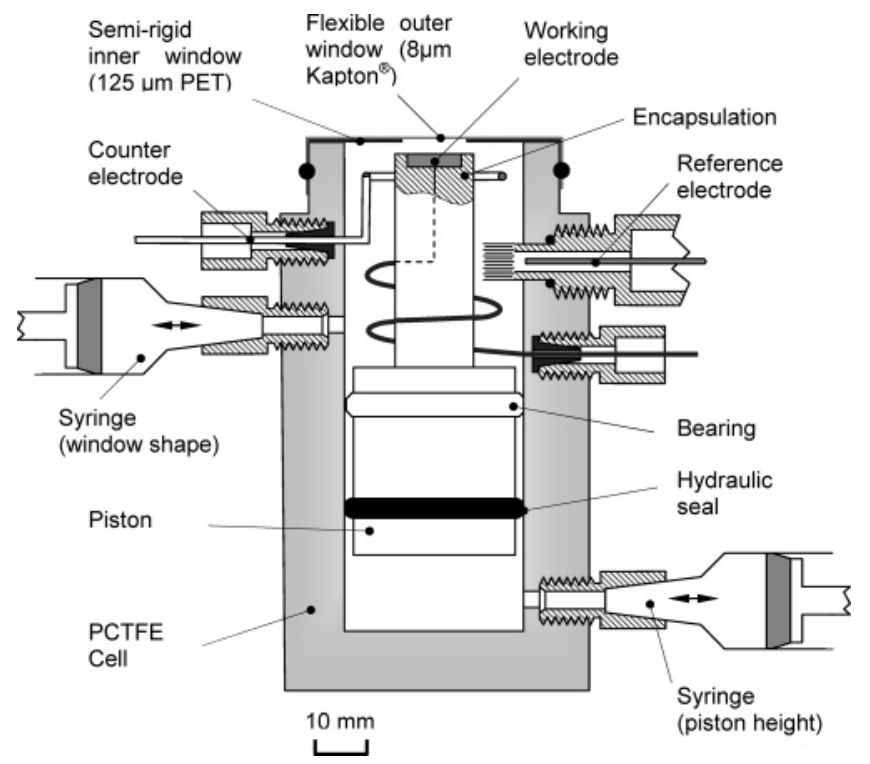

Figure 1. Schematic cross section of the electrochemical cell.

suitable designs for electrochemical cells for use in situ. The advent of array detectors and 2-D cameras, combined with increased photon fluxes of $\sim 10^{12}$ photons $\mathrm{s}^{-1}$, has also made timeresolved studies practical. As a rule, this work has concentrated on surfaces that are ideal in some way, e.g., thin layers suspended on an X-ray transparent membrane, ${ }^{17-19}$ layers that are thin or atomically flat or both, ${ }^{20,22}$ or single crystals. ${ }^{20-21,23,25}$

Here, we describe the design of an in situ cell for making timeresolved X-ray measurements correlated with $E_{\text {corr }}$, voltammetry or other electrochemical data. In contrast to previous work, the cell is intended for use with rough, heterogeneous metal surfaces, either fragments of real artifacts, where these can be used, or close simulants. The surface roughness, which may be on a scale from one $\mu \mathrm{m}$ to hundreds of micrometers, arises from the normal state of the metal or from the corrosion crust. The heterogeneity is that of a polycrystalline material, which may (in the most complex case) be a multiphase alloy, with a grain structure conditioned by manufacture (e.g., forging, casting) with inclusions and coated with several corrosion products.

Clearly, applications of the cell are not limited to cultural heritage metals. Corrosion on modern surfaces and also surface modification on technologically important electrodes (e.g., borondoped diamond) may also be studied. Neither is the cell limited to X-ray analysis. Some preliminary Raman work has also been carried out.

\section{CELl Design}

The cell (Figure 1) is basically of the Bragg type ${ }^{20}$ and is designed for use with working electrodes that may be rough but flat and up to $16 \mathrm{~mm}$ across in their largest dimension. It is therefore suitable for use on beam lines with footprints from the submicrometer to the millimeter scale. The overall dimensions

(23) Davenport, A. J.; Oblonsky, L. J.; Ryan, M. P.; Toney, M. F. J. Electrochem. Soc. 2000, 147, 2162-2173.

(24) Brossard, F.; Etgens, V. H.; Tadjeddine, A. Nucl. Instrum. Methods 1997 B 129, 419-422.

(25) Zegenhagen, J.; Kazimirov, A.; Scherb, G.; Kolb, D. M.; Smilgies, D.-M.; Feidenhans'1, R. Surf. Sci. 1996, 352-354, 346-351. are $100 \mathrm{~mm}$ high by $60 \mathrm{~mm}$ outside diameter. The bore of the cell is $\sim 30 \mathrm{~mm}$. The cell may be used in any orientation, and accompanying hardware easily adapts the mounting to the requirements of different beam lines.

The large parts of the cell such as the body and the piston are machined from poly (chlorotrifluroethylene) (PCTFE), which has excellent chemical resistance and is relatively hard and dimensionally stable compared to the alternative poly (tetrafluoroethylene) (PTFE). For example, PTFE undergoes a phase transition at $\sim 19^{\circ} \mathrm{C}$ that can lead to dimensional changes of several percent ${ }^{26}$ whereas, in PCTFE, this occurs above $50{ }^{\circ} \mathrm{C} .27$

There are two main engineering problems to overcome in a cell of this type:

1. The cell is filled with corrosive liquid, must be rotated during some types of analysis, and to be sufficiently flexible, must adapt to different beam lines where the surface orientation required might be horizontal or vertical. Leakage from the cell can potentially cause serious damage to expensive goniometers and other equipment.

2. For the electrochemical processes to work properly, there needs to be a low impedance path from the surface of the working electrode through the electrolyte to both the counter and reference electrodes, and the impedance should not vary significantly from one point on the surface to another, or reaction rates will differ. At the same time, the thickness of electrolyte covering the surface cannot exceed $200 \mu \mathrm{m}$ during analysis or excessive scattering and absorption will occur in the liquid at typical X-ray energies below $13 \mathrm{keV}$.

While cells have been designed ${ }^{24}$ with stationary electrodes and long paths in the fluid for use with X-ray energies above 20 $\mathrm{keV}$, such beam energies are not commonly available, and in any case, a cell with this restriction would be of no use for XAS of many elements of interest.

To overcome the first problem, it is common practice to use a fully closed cell where the X-rays enter through a thin polymer membrane that retains the fluid in any orientation. We have used either 8- $\mu \mathrm{m}$ Kapton HN (Goodfellow Ltd.) or 10- $\mu \mathrm{m}$ low-density polyethylene "cling film" (Sainsburys plc) (The latter has diffraction peaks that interfere, for example, with cuprite, but is useful for XAS and where optical transparency is required). In both cases, oversize circles cut from the material are stretched over the top of the cell and sealed with an external O-ring (Figure 1). With practice, this operation can be carried out in a few seconds. No windows have failed so far, and they are mechanically reliable and radiation tolerant up to flux densities of $\sim 3 \times 10^{14}$ photons $\mathrm{cm}^{-2} \mathrm{~s}^{-1}$ at $9 \mathrm{keV}$ for several days. An inner window or spacer with a rectangular hole in the center is formed from a disk of poly(ethylene terephthalate) (PET) $100-200 \mu \mathrm{m}$ thick, held in place by the outer window in a shallow recess in the top of the cell. External feed-throughs for wire and liquid use 6-mm PTFE "flangeless" HPLC fittings (Upchurch Scientific Inc.) fitted to ports machined directly into the cell wall or custom-designed Viton

(26) Takenaga, M.; Obori, H.; Yamagata, K. J. Polym. Sci. Lett. 1985, 23, 4547.

(27) Waller, J. M.; Newton, B. E.; Beeson, H. D.; Hass, J. P. In Flammability and Sensitivity of Materials in Oxygen Enriched Atmospheres: ASTMSTP139; Steinberg, A. T., Newton, B. E., Beeson, H. D., Eds.; American Society for Testing of Materials: West Conshohocken, 2000; Vol. 9, p 21. 


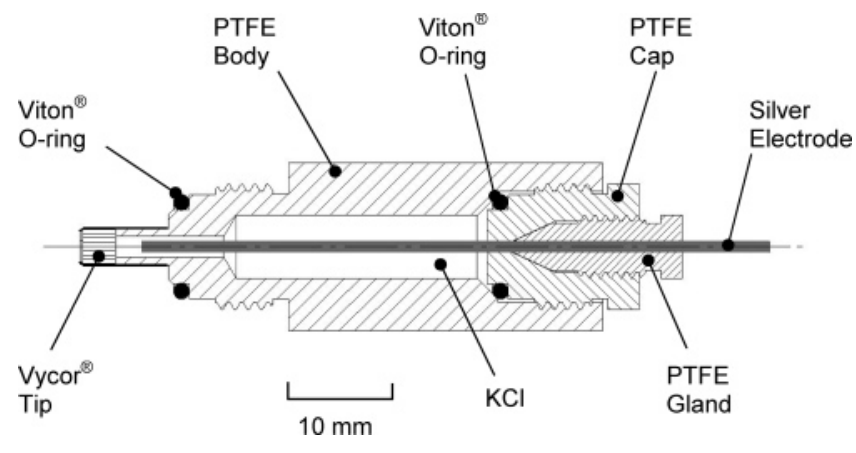

Figure 2. Cross section of the custom-made $\mathrm{Ag} / \mathrm{AgCl}$ reference electrode. Apart from the Vycor tip and the silver electrode, components are machined from PTFE.

O-ring seals. The variety of ferrules available with the HPLC fittings facilitates their use as electrical or liquid feed-throughs.

To overcome the second problem, the working electrode was mounted on the end of a piston that can be moved hydraulically (using the electrolyte as the working fluid) or mechanically. For $\mathrm{X}$-ray analysis, the working electrode is brought into contact with the inner window, and the PET gives first-order control over the thickness of the fluid pocket. The geometry of the aperture ensures that the working electrode surface remains in contact with the bulk of the electrolyte-albeit through a restricted path. (Similar strategies have been used from the earliest experiments.) ${ }^{16}$ Second-order control of electrolyte thickness is achieved by setting a small negative or positive hydrostatic pressure in the top of the cell (not sufficient to "unstick" the piston) using the syringe above the piston in Figure 1. This controls the negative or positive curvature of the outer window above the working electrode surface and, hence, the fluid thickness. Retracting the piston moves the working electrode to an "electrochemical position" where ion transport is not restricted by the limited volume of fluid in the pocket. Time-resolved studies demand that movement between the two positions can be repeated under remote control. For this purpose, upper and lower syringes (Figure 1) are used to inject and remove liquid from above and below the piston so that the total cell volume remains constant. An alternative would be to use a closed circuit reversible pump to transfer fluid from one side of the piston to the other.

The working electrode may be between 1 and $10 \mathrm{~mm}$ thick and is encapsulated in epoxy or acrylic resin so that only the top surface is exposed to the electrolyte. As usual, it may be reused by polishing back the surface ex situ using standard metallographic techniques.

Since the cell has to operate in environments where space is restricted, we tested some commercially available miniature $\mathrm{Ag}$ / $\mathrm{AgCl}$ reference electrodes. These were not well sealed, and excessively fragile, so a robust custom design using 1-mmdiameter 99.95\% pure silver wire (Alpha Chemicals Ltd.) was developed (Figure 2) and fitted with a Vycor porous tip of $\sim 3.2$ $\mathrm{mm}$ diameter (Bioanalytical Systems Inc.).

The counter electrode is a 30-mm-diameter ring of 1-mmdiameter 99.95\% pure Pt wire supported by an HPLC fitting.

Since beam time is at a premium, all electrodes may be changed in $1 \mathrm{~min}$ or so, and the cell may be flushed and the electrolyte changed in under $10 \mathrm{~min}$.

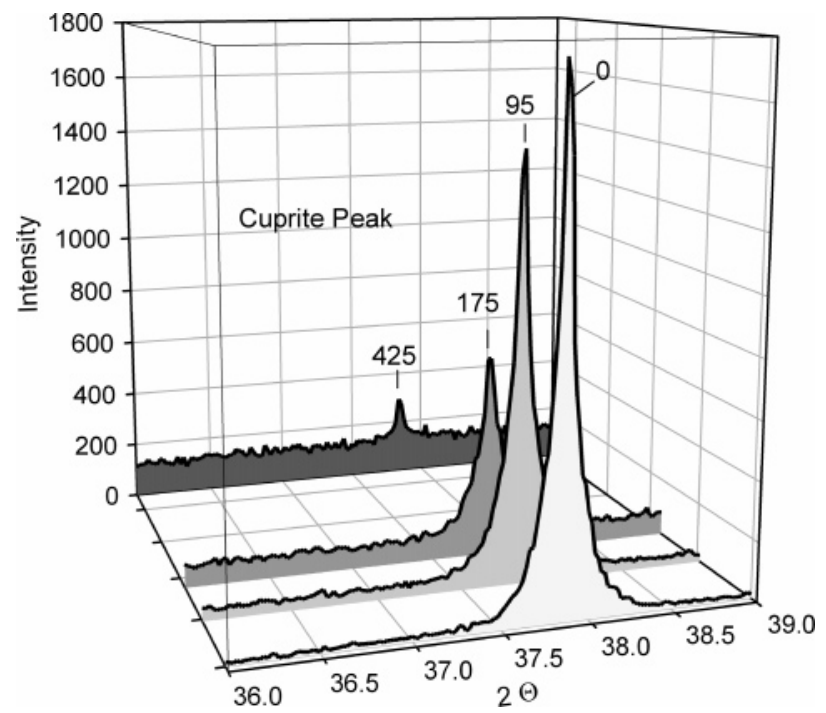

Figure 3. Cuprite peak intensity as a function of fluid pocket thickness. The incident X-ray angle was fixed at $20^{\circ}$ to the surface.

\section{OPTIMIZATION AND EXPERIMENTAL DETAILS}

Preliminary experiments were performed on station 2.3 at SRS (Daresbury Laboratories). A monochromatic beam with a wavelength of $1.6 \AA$ was used. Slits were positioned so that an area of $2 \mathrm{~mm}^{2}$ was analyzed. Typically, the detector scanned the $2 \Theta$ range $24-50^{\circ}$ with a step size of $0.02^{\circ}$ (counting time $1 \mathrm{~s} / \mathrm{step}$ ). The photon intensity was in the range $10^{9}-10^{10} / \mathrm{s}$, and each spectrum took 20-30 min to collect. At this stage, therefore, raising and lowering the working electrode was not worthwhile. Simultaneously, electrochemical data were collected using a CHI1232 handheld potentiostat (IJ Cambria Scientific Ltd.). The $\mathrm{Ag} / \mathrm{AgCl}$ electrode described earlier in this article was used as reference electrode (220 mV vs normal hydrogen electrode).

The operation of the cell was tested using inner windows of various thicknesses and, therefore, various thicknesses of electrolyte between the sample and the outer window. For the electrochemical processes, it is essential that enough fluid is present around the working electrode so that the transport processes taking place in the electrochemical cell remain as undisturbed as possible. On the other hand, the fluid layer will absorb and scatter incoming and reflected X-rays, resulting in poor peak-to-background ratios and broadened peaks. Both aspects need to be taken into account.

Experiments were performed on a copper sample covered with a cuprite layer $\left(\mathrm{Cu}_{2} \mathrm{O}\right)$ having a thickness in the order of several tens of micrometers. Four different setups were tested $(425,175$, and $95 \mu \mathrm{m}$ and without window), while the cuprite peak at a $2 \Theta$ value of $37.8^{\circ}$ was monitored. Figure 3 shows the background increase and peak intensity decrease as a function of window thickness. The peak maximum intensity (normalized to the intensity without window), plotted as a function of the window thickness (Figure 4) shows that for a window of $95 \mu \mathrm{m} 80 \%$ of the original intensity remains. This value decreases rapidly for thicker windows: 175 (40\%) and $425 \mu \mathrm{m}$ (16\%). Figure 4 also shows the signal-to-background ratio as a function of window thickness, which exhibits an exponential decrease as a function of increasing window thickness. In practice, the thickness of the fluid pocket will be locally modulated by the surface roughness, 


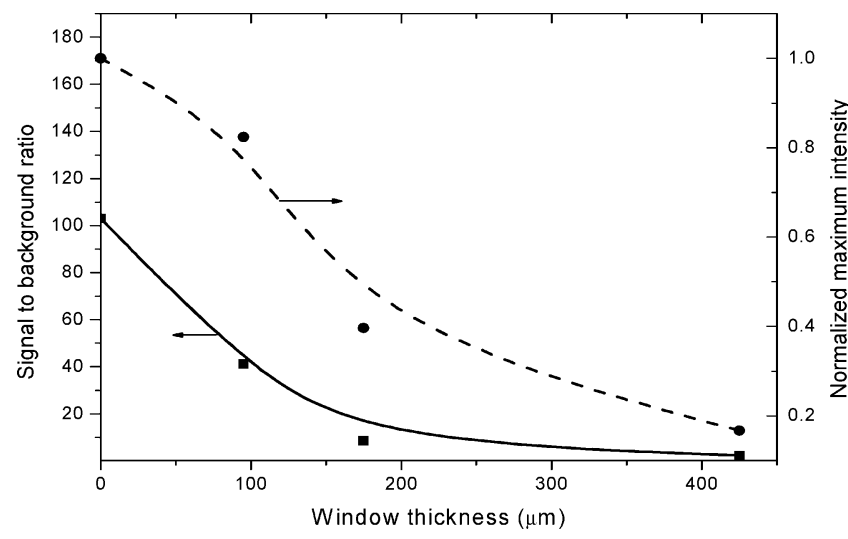

Figure 4. Signal-to-noise ratio and normalized maximum intensity for the cuprite peak at $2 \Theta \sim 37.8^{\circ}(\lambda=0.16 \mathrm{~nm})$ as a function of fluid pocket thickness.

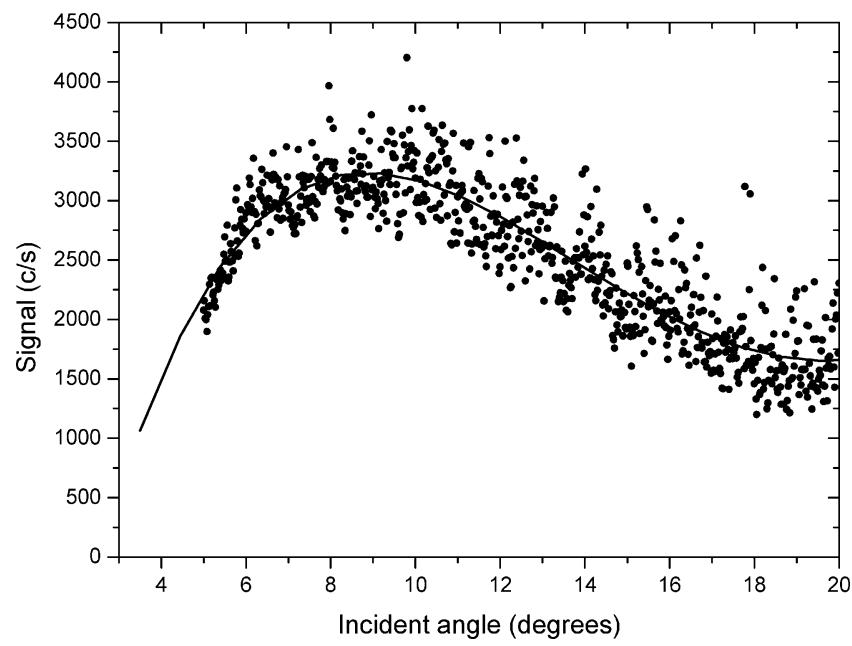

Figure 5. Intensity of the cuprite peak as a function of incident X-ray angle (measured from the surface) for a thin cuprite layer on copper and for a fluid thickness of $175 \mu \mathrm{m}$. The optimum incident angle, giving a good compromise between scattering and surface sensitivity was taken as $10^{\circ}$.

so that the thickness determined by the inner window represents a minimum value.

The surface sensitivity of the measurements was optimized on the same sample by changing the incident angle $\left(5-20^{\circ}\right)$ while monitoring the cuprite peak $37.8^{\circ}$. Here, we used an inner window of $175 \mu \mathrm{m}$. Figure 5 shows a polynomial fit of these data indicating a maximum surface sensitivity at $7-10^{\circ}$ to the surface plane.

Subsequent measurements reported here were carried out using a fixed incident angle of $10^{\circ}$ and an inner window of 175 $\mu \mathrm{m}$. (Recently, we have reduced this to $125 \mu \mathrm{m}$.)

\section{MONITORING THE TRANSFORMATION OF NANTOKITE TO CUPRITE}

To test the cell in applications, a set of experiments was performed to study the change of patina on copper-based artifacts during their storage in a sodium sesquicarbonate solution.

Copper-based archaeological artifacts recovered from wet environments (buried or marine conditions) are often covered with a natural patina highly appreciated for its æsthetic value. This patina is quite unstable, especially when it contains chloride species. Indeed, the underlying metal will corrode at an accelerated rate in the oxygen-rich air. ${ }^{28}$ Therefore, it is best to store these objects in a solution until some treatment can be applied. They are usually stored in tap water or a sodium sesquicarbonate solution. ${ }^{29-31}$ Several other methods for stabilizing corroded copper alloys are used as well, such as washing the objects in alkaline dithionite, in citric acid inhibited with thiourea, or in aqueous acetonitrile. However, the use of tap water or a sodium sesquicarbonate solution remains the most common method, since this procedure proves to be the least damaging to the patina. ${ }^{28,30}$ Nevertheless, the artifacts often remain unstable, and there is a significant risk of chemical transformation of the natural patina and development of active corrosion. ${ }^{32,33}$ Consequently, monitoring of the treatments remains necessary.

Here, we examine the monitoring of corrosion potential, $E_{\text {corr }}$, for this application. ${ }^{34}$ The method is easy to use and relatively low cost and may therefore be suitable for museum applications. The hypothesis is that the $E_{\text {corr }}$ value remains stable when there are no changes in the surface composition. However, the method is not yet optimized or studied in detail for this type of application. We therefore set out to determine whether $E_{\text {corr }}$ measurements can be used to monitor the corrosion behavior of copper-based alloys during their storage and stabilization, using time-resolved, in situ SR-XRD to measure chemical changes in the surface and at the same time recording the $E_{\text {corr }}$ data. Nantokite, which is considered to be the main catalytic agent for active corrosion, ${ }^{28}$ was used as an example here.

A pure copper substrate covered with nantokite $(\mathrm{CuCl})$ was obtained by immersing samples for $1 \mathrm{~h}$ in a saturated $\mathrm{CuCl}_{2} \cdot 2 \mathrm{H}_{2} \mathrm{O}$ solution. After rinsing with deionized water they were exposed to the atmosphere for a night. ${ }^{35}$ The quality of the corrosion layer was checked using powder XRD.

Various concentrations of sodium sesquicarbonate solutions are used by conservators for the stabilization of bronze artifacts. For example, 5-10 wt \% solutions were very common, but due to side effects, such as the formation of chalconatronite $\left(\mathrm{Na}_{2} \mathrm{Cu}\right.$ $\left.\left(\mathrm{CuO}_{3}\right)_{2} \cdot 3 \mathrm{H}_{2} \mathrm{O}\right)$, lower concentrations are now used..$^{28,30,31}$ For this study, a $1 \mathrm{wt} \%$ sodium sesquicarbonate solution was prepared by dissolving $11.89 \mathrm{~g} / \mathrm{L} \mathrm{Na} \mathrm{CO}_{3} \cdot \mathrm{NaHCO}_{3} \cdot 2 \mathrm{H}_{2} \mathrm{O}$ in deionized water (pH 10).

The $E_{\text {corr }}$ data, plotted as a function of time (Figure 6), first undergo a strong increase during $\sim 25 \mathrm{~min}$ after which the value fluctuates slightly between -0.05 and $-0.03 \mathrm{~V}$ during the next $105 \mathrm{~min}$. After a period of $130 \mathrm{~min}$, they start to decrease. The arrows across the bottom of the plot show the time correlation with the XRD scans, which lasted $\sim 30$ min each. These are plotted in Figure 7, showing nantokite, cuprite, and copper peaks as expected. There has been a decrease in the background level

(28) Scott, D. A. Copper and Bronze in Art: Corrosion, Colorants, Conservation; The Getty Conservation Institute: Los Angeles; 2002.

(29) Oddy, W. A.; Hughes, M. J. Stud. Conserv. 1970, 15, 183-189.

(30) MacLeod, I. D. In Proceedings of the 8th triennial ICOM-CC meeting, Grimstad, K., Ed.; The Getty Conservation Institute: Los Angeles, 1987; pp 1079-1085.

(31) MacLeod, I. D. Stud. Conserv. 1987, 32, 25-40.

(32) Pollard, A. M.; Thomas, R. G.; Williams, P. A. Stud. Conserv. 1990, 35, 148-152.

(33) Horie, C. V.; Vint, J. A. Stud. Conserv. 1982, 27, 185-186.

(34) Oldham, H. B.; Myland J. C. Fundamentals of Electrochemical Science; Academic Press: San Diego, 1994.

(35) Lamy, C. Stabilisation d'objets archéologiques chlorurés en alliage cuivreux - Définition des conditions d'une polarisation cathodique à potentiel constant en solution de sesquicarbonate de sodium 1\%. Unpublished Rapport de Stage, Université de Nantes, 1997. 


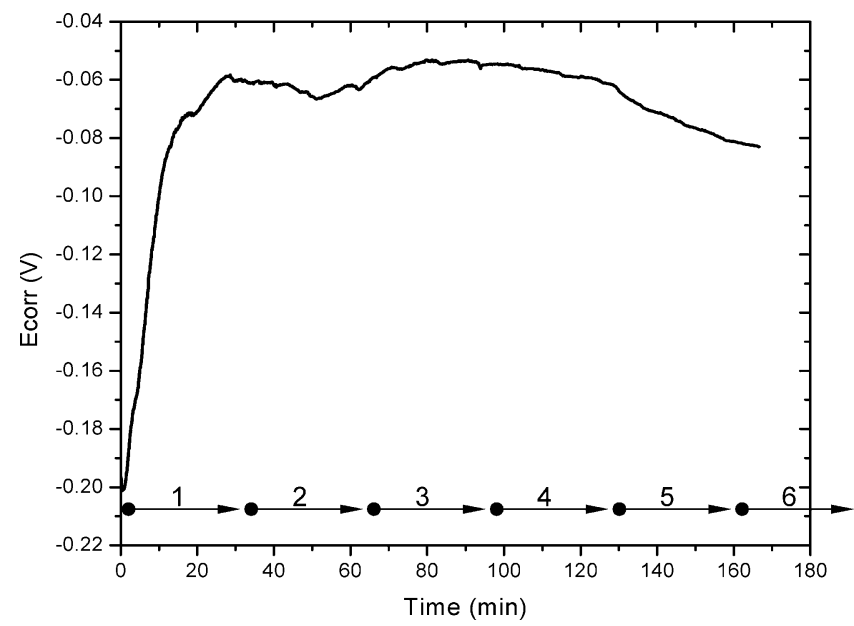

Figure 6. Corrosion potential $\left(E_{\text {corr }}\right)$ data recorded while the $X$-ray spectra were in progress. The arrows show the time correlation between the spectra and $E_{\text {corr }}$.

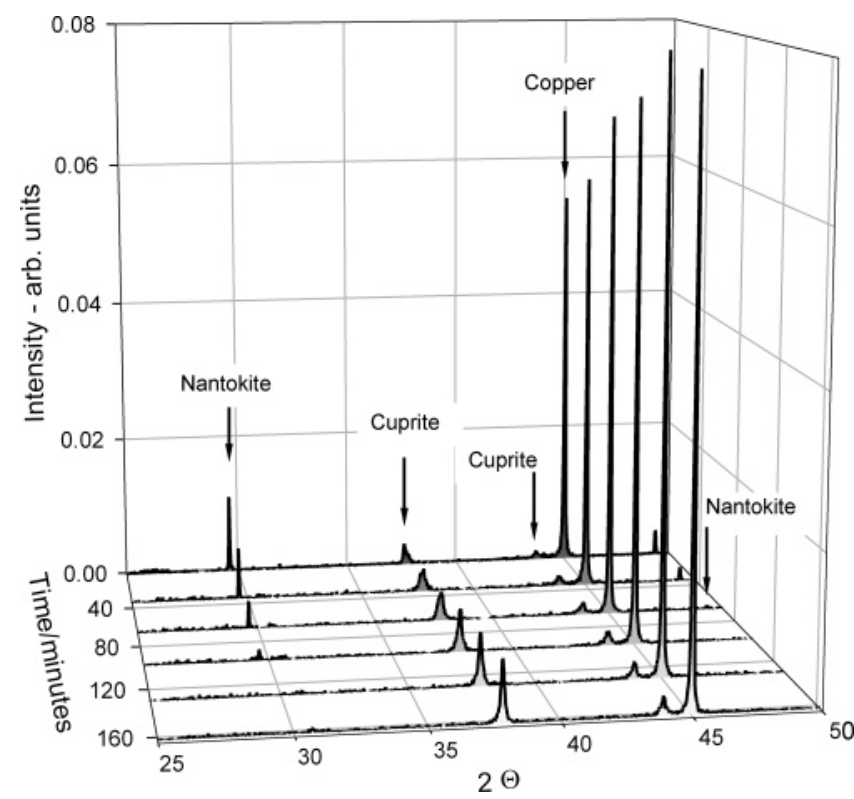

Figure 7. Cascade plot showing the successive time-resolved spectra. The background has been left in place to show the effect of the window and fluid. It is evident that the thickness of the fluid pocket decreased slightly over the total elapsed time.

during the experiment corresponding to a decrease in the thickness of the fluid pocket, probably due to differential thermal expansion of the cell and the electrolyte. Most of this effect occurs during the first spectrum and means that the initial decrease in the nantokite peaks is underestimated, while the increase in the cuprite is overestimated. However, as the thickness change is small during the rest of the experiment, and as the thickness was changing as the first spectrum progressed, we did not attempt to correct for this. The behavior of the peak areas as a function of time is shown in Figure 8. The background was fitted with a spline and subtracted before calculating these. The symbols show the measured areas, while the lines are fits to the data. Decaying signals were well fitted by a negative exponential of the form

$$
I=I_{0} \mathrm{e}^{-a t}
$$

where $I_{0}$ is the initial area, $t$ is time, and $a$ is a fitting parameter.

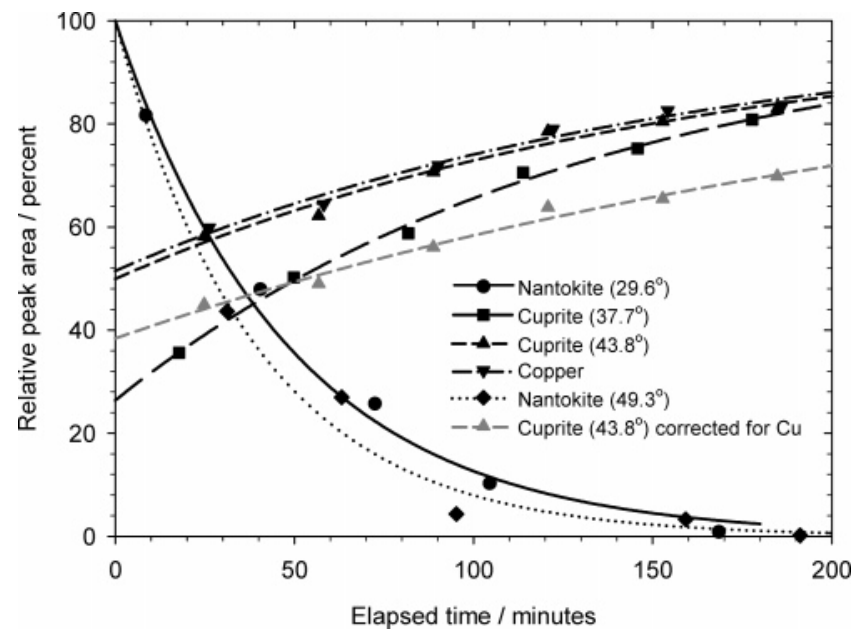

Figure 8. Dependence of peak area on time elapsed from the start of the experiment (the moment the electrode was wetted). The background was fitted and subtracted before calculating the area. The symbols show the measured data while the lines show a threeparameter exponential growth to maximum fitted to the increasing data, and a two-parameter exponential decay fitted to the decreasing data (see text). The peak areas are expressed as a percentage of the asymptotic value for the former, and the initial value for the latter.

Increasing signals were fitted with

$$
I=I_{0}+a\left(1-\mathrm{e}^{-a t}\right)
$$

To display the curves for comparison, decaying curves (the nantokite peaks) are plotted as a percentage of their initial value $(t=0)$, while increasing curves (cuprite and copper) are plotted as a percentage of their asymptotic value $(t=\infty)$.

The behavior of the two nantokite peaks is identical within the noise on the data. Comparison with Figure 7 shows that after $\sim 130$ min the nantokite has disappeared into the background. Additionally, since one peak is recorded close to the beginning, and the other close to the end of the spectrum, their similar behavior indicates that the change in thickness of the fluid layer did not seriously distort the time dependence of the peak areas. The isolated cuprite peak at $2 \Theta \sim 37.7^{\circ}$ (filled squares and long dash line), however, behaves quite differently from the peak close to the copper at $\sim 43.8^{\circ}$ (filled triangles and short dashed line). Indeed, the latter behaves in a manner almost identical to that of the copper peak (inverted filled triangles). The copper peak was fitted with a Lorentzian and subtracted to correct the cuprite intensity (gray curve, filled triangles), but the difference in behavior remains. The cuprite peaks (unlike the other peaks in the spectrum) both exhibit a steady increase in their $2 \Theta$ value of $0.25^{\circ}$ over the whole experiment). From these observations, it seems clear that there is a change in both structure and preferred orientation of the cuprite as the layer grows.

Comparison of Figures 6 and 8 shows that changes in $E_{\text {corr }}$ are not well correlated with the X-ray measurements, and on this basis, one would conclude that the corrosion potential is not a reliable indicator of the surface state. ${ }^{36}$

The experiment was repeated subsequently with different X-ray doses, but with no sign that the chemistry is affected by the 
radiation. Visual inspection also showed that the surface modification had taken place inhomogeneously, although in a pattern with no correlation to either the experimental geometry or the X-ray footprint. Despite the possibly restricted electrochemical access to the sample surface, the $E_{\text {corr }}$ data are similar to those recorded with the working electrode deeply immersed in the electrolyte. Nevertheless, the fact remains that the X-ray data come from a relatively small area of the surface, while the electrochemical data are averaged over the whole. Clearly, this is a feature of the experiments that needs to be addressed in future, for example, by using a faster sampling station such as 6.2 at SRS, 37 and integrating X-ray measurements from different regions of the surface.

\section{CONCLUSIONS}

The electrochemical cell described here forms the basis of a measurement system for the in situ study of surface corrosion of real metals with realistic surface conditioning using SR-X-rays and other photon sources to obtain time-resolved surface chemical and structural information while collecting electrochemical data in parallel. The cell is easily adapted to full automation, and we are currently working on a laptop-based data and control system that interfaces with a custom potentiostat with interleaved stepper motor control for the piston and window adjustments and provision for the direct triggering of fast X-ray measurements. The same system will also make a visual record of the experiments and, in particular, the sample surface, using a webcam.

The cell is leak-tight in operation, will work in any orientation, is easily maintained, and has a turnaround time of a few minutes (essential for the efficient use of synchrotron time). It is easily

(36) Leyssens, K.; Adriaens, A.; Dowsett, M. G.; Schotte, B.; Oloff, I.; Pantos, E. Bell, A. M. T.; Thompson, S. P. Electrochem. Commun. 2005, 7, 12561270 .

(37) Cernik R. J.; Barnes, P.; Bushnell-Wye, G.; Dent, A. J.; Diakun, G. P.; Flaherty, J. V.; Greaves, G. N.; Heeley, E. L.; Helsby, W.; Jacques, S. D. M.; Kay, J.; Rayment, T.; Ryan, A.; Tanga, G. C.; Terrilla, N. J. J. Synchrotron Radiat. 2004, 11, 163-170. adapted to the mounting requirements of the beam-line. The thickness of the electrolyte pocket over the sample may be changed over the range $0-1 \mathrm{~mm}$ to obtain the optimum balance between electrochemistry and X-ray requirements. However, the actual fluid thickness will vary from point to point over a rough sample, and this may influence which parts of the sample are actually seen in the X-ray spectrum. In addition, the working electrode may be withdrawn into the bulk of the electrolyte when required. It is clear from the behavior of the background in Figure 7 that it is desirable to keep the fluid pocket thickness under control during the acquisition of the X-ray data, and the cell will be modified so that this is the case. In addition, fast spectrum acquisition on a time scale short compared to that of any thermomechanical instability in the cell would be an advantage in future experiments, since peak intensity corrections could be applied if required.

The example application demonstrates the parallel collection of X-ray and electrochemical data, but also shows that it is important with intrinsically inhomogeneous surfaces to ensure that the data are averaged over the same areas.

\section{ACKNOWLEDGMENT}

The authors gratefully acknowledge the following for their help: Derrick Richards and Pieter van Hoe (cell construction); Tony Bell, Steve Thompson, and Manolis Pantos (SRS Daresbury); Karen Leyssens and Bart Schotte (Ph.D. students), Ieuan Jenkins, IJ Cambria Scientific Ltd, (loan of the potentiostat), Drs. C. Degrigny, J. V. McPherson, J. Robinson, and R.F. Pettifer and Profs. E. Temmerman and P. A. Thomas (advice and discussions). M.G.D. thanks Cameca GmbH for their financial support.

Received for review December 4, 2005. Accepted March 15, 2006.

AC052125Y 